\title{
OUTCOME BASED LEARNING: INVESTIGATING THE EFFECT OF EXPERIENTIAL LEARNING ACTIVITY-BASED INSTRUCTION ON STUDENTS
}

\author{
Prashant Thote $1 \bowtie$ (iD), Gowri. S. \\ ${ }^{1}$ Gyanodaya Vidya Mandir, India
}

Received 10 November 2021

Accepted 29 December 2021

Published 31 January 2022

\section{Corresponding Author}

Prashant Thote,

prashant.thote@rediffmail.com

DOI

10.29121/granthaalayah.v10.i1.2022 .4447

Funding: This research received no specific grant from any funding agency in the public, commercial, or not-for-profit sectors.

Copyright: (C) 2022 The Author(s). This is an open access article distributed under the terms of the Creative Commons Attribution License, which permits unrestricted use, distribution, and reproduction in any medium, provided the original author and source are credited.

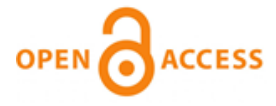

\section{ABSTRACT}

"Change in the classroom is the change in world"

Understanding the scientific concept is central in school education. To enhance the deep conceptual understanding- teaching- learning method that is adopted at school by teachers play a significant role. The conventional teaching approach is often used by the schoolteachers because it is easy and due to lack of other alternative teaching-learning approaches. The present study is conducted to compare the experiential learning method with conventional method. The experimental research design is employed in the study. Totally 40 students participate in the study. Sample is drawn by using Purposive convenient sampling technique. Students are categories into two: study and control group. Each group consists of 20 students. Study is conducted in a co-educational school. Data is collected by using questionnaire. Descriptive statistical method is used to collect the data. Result of the study depicts that experiential learning activity model enhances the academic performance and deep theoretical understanding to attain intended specific learning outcome than the conventional method of teaching-learning. The statistical data clearly illustrates that there is noteworthy difference in the performance of both groups. Researchers supports the amalgamation of experiential learning approach at the foundation level will change the dynamics of education system in the modern technological era.

Keywords: Experiential Learning, Conventional Teaching Approach, Cognitive Framework, Deep Conceptual Understanding, Competence Based Learning

\section{INTRODUCTION}

"Education means all round drawing out of the best in the child and man in body, mind and spirit" - Mahatma Gandhi

Activities that are developed when teaching- learning Science, aims to encourage the students to observe and explore their environment; to understand the relationship between man and nature and to understand human being as an integrated part of human chain. Learning Science will be more fun when it is based on real life experiences. Science learning is a process, just hearing and seeing is insufficient to learn the concept. Students enhance their conceptual understanding by hands- on activities.

Intellectual development is a vital aspect and is directly related with science. Students must develop their skills, understand concrete operations in logical fashion and must be able to classify and understand their causal relationship. An effective teaching-learning process with an efficient mean of feeding can provide motivation to the learners. 
The joyful learning is a teaching-learning pedagogy that is adapted for the psychological and cognitive development of a child by providing them a pleasant climate for learning. Learning process can be done in relax and carefree way and students must have motivation for learning. Joyful learning brings spark in the eyes of the students, excite, and empower them to engage with learning experience in fun filled and play manner.

Joyful learning is a positive, rational, and emotive state of students. Learning experience is achieved through deriving pleasure and sense of contentment from the process of learning. The experiential learning activity is based on the meaningful world built on learners' prior knowledge, experience and actively involves them in rich task that may help them achieve the conceptual understanding, transferrable knowledge, and skills. Experiential learning activities are the major learning strategies that are intertwined with explicit instruction and well- scaffolding opportunities to practice and apply learning. Well-fabricated collaborative learning opportunities motivate students to probe questions, explain and express their thoughts and find solutions.

Joyful learning approach is very useful in the holistic development - intellectual, social, emotional, physical, artistic; create values and feeling amongst the children. It is pretty development of entire thoughts and feelings. It is a strategy, concept, and practice of learning for meaningful constructivism and active learning. Instructional material facilitates effect teaching-learning and encourages and motivates students.

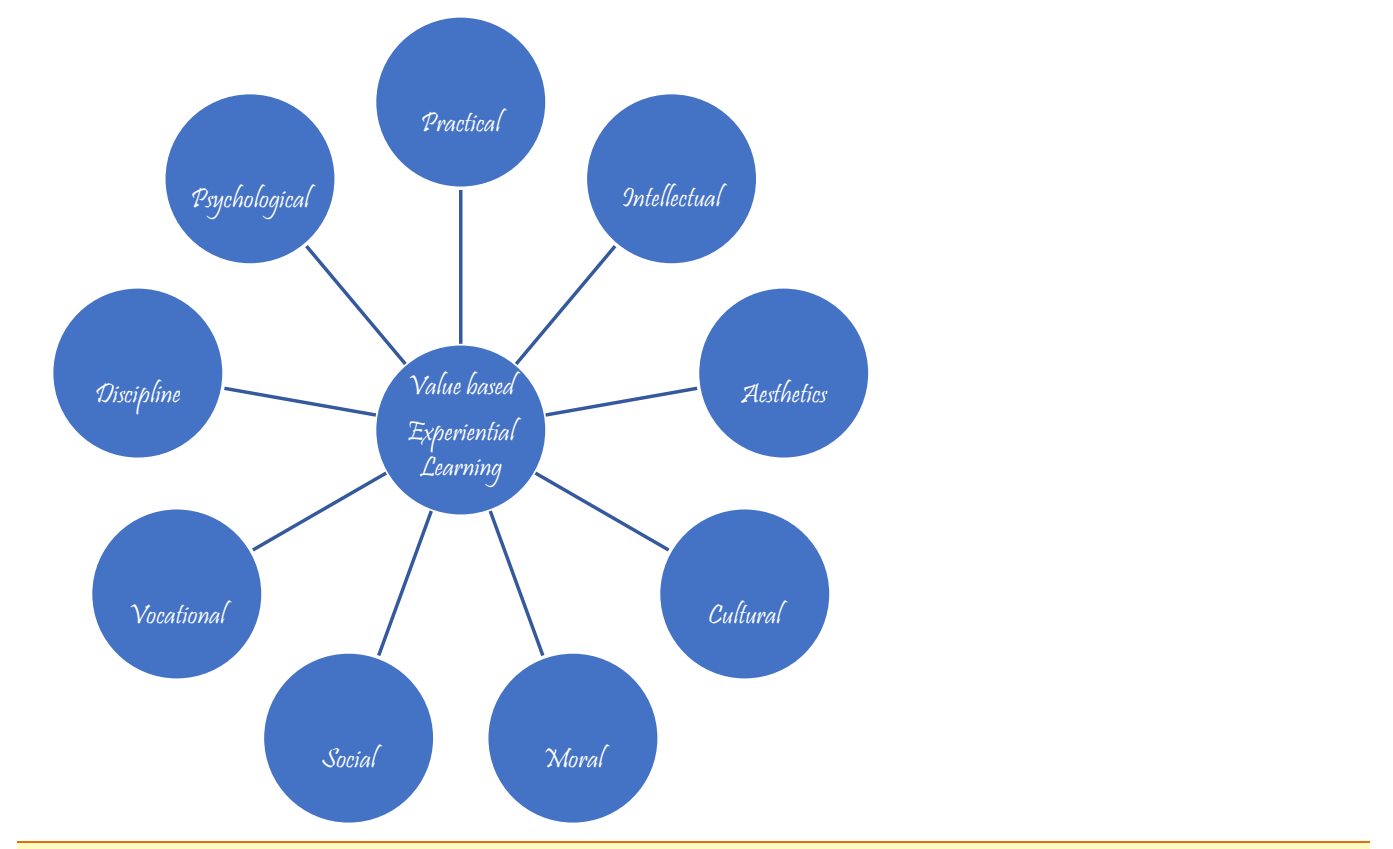

Figure 1 Value based Experiential Learning

Experiential Learning Activity:

Focus: science

Grade: IX

\section{Focus Attention}

- What is density?

- What is pressure?

- What is buoyance?

- What is volume? 
- How these variable changes if one of their values increases or decreases?

\section{Specific Learning Outcomes}

- Student will be able to define the properties of density, buoyancy, pressure, volume, and all variables of Boyle's law.

- Learners will be able to apply Archimedes principle and Boyle's law

- Learners will be able to design their own experimental model to manipulate, observe, predict, and communicate the result in case of both success and failure.

\section{Materials required}

- Empty two litters bottle

- Water

- Eye dropper

- Disposable pipettes

- Paper clips

- Balloons

- Fishing weights

- Neoprene

Teaching Time: 45 Minutes

Seating Arrangements: Two students in a group

Venue: Chemistry lab

\section{Terms Used}

\section{Mass}

Measures the quantity of matter of the body or object contains.

\section{Density}

Mass per unit volume of an object.

\section{Volume}

The total space occupied by three-dimensional object

\section{Buoyance}

It is an upward force exerted by the fluid over the surface, contact of an object which is immersed in the fluid

\section{Pressure}

It is force/unit area. It is the measurement of hotness or coldness in the body

\section{Archimedes principle}

The upward buoyance force that exerts on the object immersed in a fluid when fully/partially submerged and is it equivalent to the weight of the fluid that body display and act in upward direction at the centre of mass of displaced fluid.

\section{Buoyance compensation device}

It is a piece of diving equipment that control diver's overall buoyance allowing diver to achieve neutral buoyance while remaining at constant depth.

\section{Procedure for experiential learning activity}

Instructions (for students): observe the below experiment and design hypotheses in your own words. 


\section{Experiment}

- Take used empty two litter bottle.

- Clean it properly.

- Fill up the bottle with enough water (70 to $80 \%$ approx.)

- Drop the disposable pipette inside the bottle - pipette will start floating.

- Refill the bottle with water, until the pipette reaches the top.

- Reduce the volume of the water by squeezing the bottle. Now the pipette inside the bottle will sink.

\section{Design: Neutrally Buoyancy Pipette}

- Remove the end of the plastic pipette with scissor.

- Insert fishing weight at one end and secure it.

- Balance the buoyance by adjusting the air inside the pipette.

\section{Application of knowledge and skill to real life situation}

Students are instructed to create their own model.

- Draw the rough sketch of the design in a piece of paper.

- Design the model with the available materials.

- Use innovative and creative ideas to design Cartesian diver. (To make the learning activity more joyful.

- Make the hypotheses for the model: whether the object will float or not? and why? With reason.

- Come forward and drop the designed model inside the bottle filled with water.

- Observe: if the object sinks state the reason.

If not find the error in the design, so that the object should float

- Cover the bottle once the object starts floating.

- Squeeze the bottle and observe the change.

Recapitulation: (ask the following questions to the students)

- Which model is not successful?

- What are the alternatives made to make it more successful? (Problem solving approach)

- Which is the most successful model? And explain the structure. (HOTS)

- On squeezing the object sinks and after releasing the object floats, why? (Identify the dependent and independent variables. Cause and effect relationship)

- How the knowledge acquired about the pressure and volume is helpful in designing the experiment? (Competence based approach)

- Will the object float in the sea water as it does in the fresh water? Hot water? 


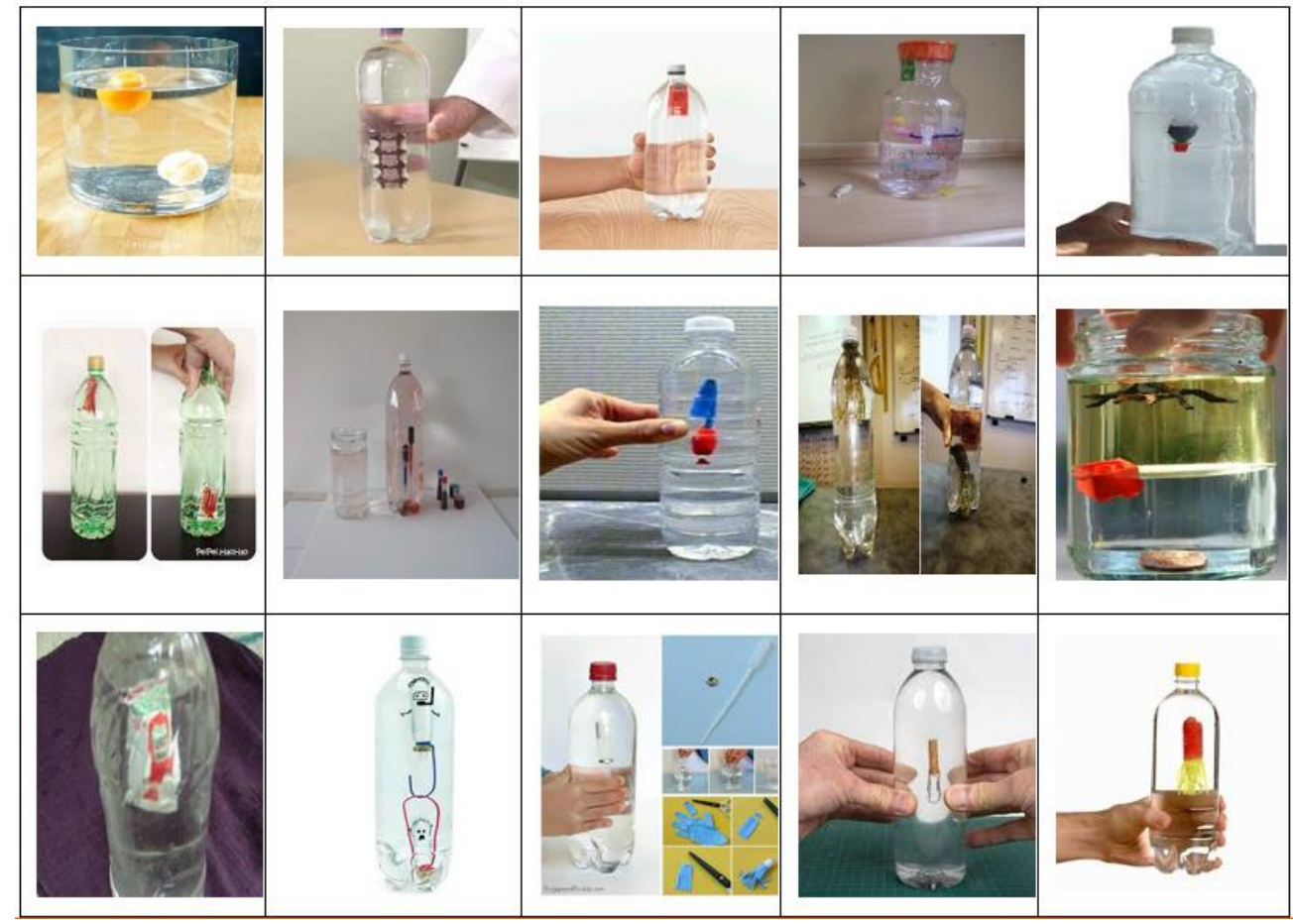

Figure 2 Reference Model

\section{OBJECTIVE OF THE STUDY}

The aim of the present paper is to compare the effectiveness of experiential learning activity to enhance the conceptual understanding of Archimedes principle and Boyle's law with conventional teaching approach.

\section{Research Question}

What is the effect of experiential learning activity-based instruction on the academic performance of the students in science?

\section{Hypothesis}

The following research null hypothesis is designed to collect the data

Research question posed null hypothesis is tested at alpha 0.05 level of significance.

$\mathbf{H}_{\mathbf{0}}$ 1: There is no vital variance in the mean achievement score of both study group and control group whether they are taught by experiential learning activity or by conventional teaching method

\section{METHOD}

\section{Research design}

Qualitative research design with non-equivalent group is used. It includes pretest and post- test with study group and control group, where E1 is control group and $X$ represents study group.

\begin{tabular}{llll}
\hline \multicolumn{3}{l}{ Table 1 Design of experiment } & \\
\hline Group & Pre-test & Treatment & Post-test \\
\hline Study Group & E1 & X & E1 \\
Control Group & C1 & - & C1 \\
\hline
\end{tabular}




\section{Sample}

Stratified sampling technique is used to draw the sample. Group A comprises of 20 girls and Group B consists of 20 boys. Random sampling technique is used to categorize the group such A1, A2, B1 and B2. Study group consists of A1 and B1 and the control group consists of A2 and B2. Each group consist of 10 boys and 10 girls. There is no vital difference between the study and the control group on previous achievement score.

\section{Tool}

Science Achievement Test (SAT) is designed by the researcher. It consists of 38 multiple choice questions. Reliability coefficient Cronbach's alpha is found to be 0.86. Each item has four distractors with one correct answer. Content validity is done by two science experts. Same instrument is used both before and after the treatment to collect the data with just change in the sequence of the items, to investigate the change in conceptual understanding of science.

\section{Data analysis}

Data is analysed by using mean score and Standard deviation. The data illustrates that the scores are normally distributed. To study the vital difference between the pre-test and the post-test the score paired, and sample $t$ test are applied. Data is analysed by using IBM SPSS 25 version. for statistical completion of mean, SD and one-way ANCOVA test.

\section{Treatment}

Two different approaches are used to teach Archimedes principle, buoyancy and Boyle's law to the learners of Grade IX. Students of the study group are taught by experiential learning activities to enhance their participation. Students of control group are taught by conventional teaching method. Same teacher delivers the instruction to both groups. Classroom observations are done through test application for both the groups. In the process of observation, students and teachers participate in teaching-learning commitment. When learning student's attitude, actions, physical and material condition of the classroom are observed.

\section{RESULT}

Table 2 Comparison between pre-test and post-test of study group and control group in Science Achievement Test

\begin{tabular}{cccccc}
\hline Variables & Groups & N & Mean & SD & Std Mean \\
Pre-test & Study Group & 20 & 8.12 & 2.729 & .611 \\
& Control Group & 20 & 8.72 & 3.167 & .711 \\
Post-test & Study Group & 20 & 24.30 & 4.137 & .928 \\
& Control Group & 20 & 17.25 & 4.110 & .918 \\
\hline
\end{tabular}

Table 3 ANCOVA analysis of pre-test and post-test score between control and study group

\begin{tabular}{|cccccc|}
\hline Variables & Sum of squares & df & Mean square & f & std \\
Pre-test & 7.756 & 1 & 7.756 & .510 & .437 \\
\hline Post-test & 103.72 & 1 & 103.72 & & \\
& 537.351 & 36 & & 6.669 & .015 \\
\hline
\end{tabular}


Table 2 illustrates that the study group performance is better than the control as per their mean and SD values. The hypothesis is evaluated by using ANCOVA analysis. Table 3 illustrates that $P>0.000$ the $\mathrm{f}$ value is 59.434 is noteworthy this means that statistically the mean score of the learners taught by using experiential learning activity have noteworthy difference from their counterparts who are taught by using conventional teaching method. Table 3 shows the difference in the achievement test in post test score of the control and study group.

\section{DISCUSSION}

1) The result of the present study reveals that there is noteworthy difference in the achievement between the learners of the study group and the control group.

2) Learners who are exposed to experiential learning activity have better performance when compared to the students taught by using conventional method.

3) It is concluded that the experiential learning activity promotes conceptual understanding, critical thinking, and problem-solving skills.

4) Experiential learning activity has very great statistically impact on the students of the study group when compared to their counterparts.

5) Students who are exposed to the experiential learning activities have the ability to apply the subject knowledge to solve day to day life challenges.

6) Experiential learning activities enhances students to be a scientific literate by designing and planning experiments, recording result, and drawing conclusions and inferences.

7) In experiential learning activity student go through series of activities which enhances their prior knowledge and conceptual understanding.

\section{CONCLUSION}

- Based on the analysis of the present study it is evident that there is a vital difference between the achievement level of students who are taught by using outcome Based Learning through experiential learning activity.

- Learners who are educated through outcome-based learning by experiential learning activity has become more successful than the students who have been educated by traditional learning method.

- When learners offer variety of learning experiences, students become actively engaged and are interested in their personalized learning process.

- Learners participate more frequently and are able to refrain more knowledge because they understand the concept in more complex ways.

- Intrusive motivation, positive self-image and sense of responsibility develop when learners become stakeholders in educational process and accept responsibility for their own actions.

- When learners become aligned to their learning and interested in their learning.

- Experiential learning activities learners to engage students through their natural curiosity, monopolize on teachable moments and enhance learners participate through their own excitement. 
- Learners actively participate in teaching-learning process of science and are able to develop positive attitude and magnified towards science they will be higher possibility to nurture high level of scientific literacy.

- Teachers should provide in-service training in system and process to amalgamate curriculum with experiential learning activities to help to create positive learning climate.

\section{REFERENCES}

Prashant Thote, An Analysis of Impact of Evidence Based Learning on Academic Achievement of Students, International Journal of Research- Granthaalayah, Vol 8, Issue- 08, August 2020. Retrieved from https://doi.org/10.29121/granthaalayah.v8.i8.2020.869

Prashant Thote, Evidence Based Learning : A Study of Impact of Experiential Learning Activities on Attainment of Specific Learning Outcomes, International Journal of Research- Granthaalayah, Vol 9, Issue- 2, February 2021.

Retrieved from https://doi.org/10.29121/granthaalayah.v9.i2.2021.3225

Prashant Thote, Evidence Based Learning : An Analysis of Impact of Experiential Learning on Attainment of Intended Specific Learning Outcome, International Journal of Research- Granthaalayah, Vol 9, Issue- 1, January 2021. $\quad$ Retrieved from https://doi.org/10.29121/granthaalayah.v9.i1.2021.2971

Prashant Thote, Evidence Based Learning : An Analysis of Impact of Remedial Teaching on Conceptual Understanding, International Journal of ResearchGranthaalayah, Vol 8, Issue- 12, December 2020. Retrieved from https://doi.org/10.29121/granthaalayah.v8.i12.2020.2606

Prashant Thote, Evidence Based Learning : An Analysis of Impact of Teacher's Design Model on Conceptual Understanding, International Journal of Research- Granthaalayah, Vol 9, Issue- 3, March- 2021. Retrieved from https://doi.org/10.29121/granthaalayah.v9.i3.2021.3702

Prashant Thote, Evidence Based Learning : An Analysis of Impact on Retention of Knowledge, International Journal of Research- Granthaalayah, Vol 8, Issue10, October 2020. Retrieved from https://doi.org/10.29121/granthaalayah.v8.i10.2020.1883

Prashant Thote, Experiential Learning : An Analysis of Impact on Academic Achievement Among Students of Grade 12, International Journal of Research- Granthaalayah, Vol 8, Issue- 09, September 2020. Retrieved from https://doi.org/10.29121/granthaalayah.v8.i9.2020.1337

Prashant Thote, Experiential Learning : Inclusive Art Education for Joyful Learning, Review of Research, Vol 8, Issue- 09, June 2019. Retrieved from https://doi.org/10.29121/granthaalayah.v8.i5.2020.88

Prashant Thote, Experiential Learning : Model for Teaching Science at Grade Nine, Research Magma, Vol-3, Issue -06, August - 2019.

Prashant Thote, Outcome Based Learning : A Panacea for Quality Education, International Journal of Research- Granthaalayah, Vol 9, Issue- 5, May- 2021. Retrieved from https://doi.org/10.29121/granthaalayah.v9.i5.2021.3909

Prashant Thote, Outcome Based Learning : An Analysis of Impact on Academic Achievement Among School Students, International Journal of Research- 
Granthaalayah, Vol 8, Issue- 11, November 2020. Retrieved from https://doi.org/10.29121/granthaalayah.v8.i11.2020.2222

Prashant Thote, Outcome Based Learning : The Effect of Experiential Learning Activities On The Attainment Of Specific Learning Outcome Among Senior Secondary School Students, International Journal of ResearchGranthaalayah, Vol 9, Issue- 4, April- 2021. Retrieved from https://doi.org/10.29121/granthaalayah.v9.i4.2021.3824 